\title{
Statistical Analysis of Draupner Wave Data
}

\author{
Do Young Kim@* \\ "Hongik University, Sejong, Korea \\ Draupner 파랑자료의 통계적 해석 \\ 김도영(* \\ "홍익대학교 조선해양공학과
}

KEY WORDS: Ocean waves 해양파, Freak wave, New Year wave, Abnormality index 이상지수, Wave statistics 파랑 통계, PCA analysis 주축해석

\begin{abstract}
In this paper, the time history of the surface elevation measured at the Draupner platform in the North Sea in 1995 is used to examine the statistical characteristics of the wave data. The wave statistics for 48 surface measurements, which contain three freak wave occurrences, are summarized. The quartiles, boxplots, correlations, and pair plots of 15 variables, along with the abnormality index, are presented. The kurtosis and skewness of the surface elevation are two variables that are highly correlated with the abnormality index, which defines freak waves. Principal coordinate analysis showed that the direction of the changes in the abnormality index agreed with the changes in the kurtosis and skewness. In addition, various wave heights, except the maximum wave height, showed a similar direction for the height changes, and various wave periods showed a similar direction for the period changes. Based on the correlations and PCA analysis, the kurtosis and skewness of the surface profiles are the two most important variables to predict the abnormality index.
\end{abstract}

\section{1. 서 론}

해양에서는 여러 가지 종류의 파도가 발생한다. 해양에서 발 생하는 파랑은 선박 및 해양, 해안구조물과 상호 작용을 일으키 며 안전한 구조물의 설계와 운영, 보호와 안전관리에 중요한 인 자이다. 해양에서 발생하는 대진폭 파랑에 대한 관심과 연구가 지속적으로 이루어지고 있다. 해양에서 발생하는 파도 중에서 일반적으로 예측되는 최대파고의 크기를 넘어서는 매우 높은 파고를 가지는 파도를 Freak wave 또는 Rougue wave(National Ocean Service, 2019)라 한다. 북해에 설치된 Draupner platform에 서 1995년 1월 1일에 발생한 'New Year Wave'라 부르는 파도는 대표적이고 널리 알려진 Freak wave이다.

Freak wave는 이상지수 $A I($ Abnormality index)를 이용해 다음 과 같이 정의 된다(Kalif et al, 2009).

$$
A I=\frac{H}{H_{1 / 3}} \geq 2
$$

여기서 $H$ 는 파고이고 $H_{1 / 3}$ 은 유의파고이다. 관측된 Freak wave
중 이상지수가 가장 큰 경우는 North Black Sea에서 발생한 파 도로 파고가 $10.32 \mathrm{~m}$ 이고 이상지수는 3.91이다(Kalif et al, 2009).

전에는 Freak wave의 발생 확률은 통계적으로 매우 작은 것으로 생각되었으나, 실제 관측된 파랑자료에서는 Freak wave가 많이 발 생하고 있다는 것이 알려져 있다(Liu and Pinho, 2004). 북해와 일본 해역에서 실측된 파랑자료를 통해서 파고를 Rayleigh 분포로 가정 하는 경우에는 Freak wave 발생확률이 낮게 평가된다는 것을 보여 주었다(Stansell, 2004; Mori et al., 2002; Mori, 2004). 그러나 Yura 해역에서 발생한 Freak wave는 파랑자료에 충분한 수의 파도 수를 포함되어 있는 경우 발생확률이 수정 Rayleigh 분포를 사용하여 충분히 예측될 수 있음을 보여주었다(Kim, 2010).

기존의 연구결과는 대부분 파랑자료에 대해서 유의파고, 최대 파고 및 영점상향통과주기 등의 몇 가지 주요한 통계자료위주 로 되어 있어 있으며, 통계 특성들이 수치로 제공되어 있지 않 고 있다. 이 논문에서는 New Year Wave가 발생한 시점인 1995 년 1월 1일부터 1월 20일까지 Draupner platform에서 계측한 48 개의 파랑자료를 통계적으로 정리하고 종합적으로 분석하여, 그 결과를 제시하여 Freak wave와 같은 대진폭파랑의 특성을 연 구하는 파랑자료를 제공하고자 한다.

Received 25 March 2019, revised 30 April 2019, accepted 13 June 2019

Corresponding author Do Young Kim: +82-44-860-2567, dykimg@hongik.ac.kr ORCID: https://orcid.org/0000-0001-9326-8839

(c) 2019, The Korean Society of Ocean Engineers

This is an open access article distributed under the terms of the creative commons attribution non-commercial license (http://creativecommons.org/licenses/by-nc/3.0) which permits unrestricted non-commercial use, distribution, and reproduction in any medium, provided the original work is properly cited. 


\section{2. 파랑자료}

이 논문에서 사용한 파랑자료는 노르웨이 근처의 북해에 설치 된 Draupner platform에서 계측된 파형의 시계열 자료이다. 이 지 역에서 1995년 1월 1일에 계측된 파고 $25.6 \mathrm{~m}$ 인 파고는 ' $\mathrm{New}$ Year Wave'라고 잘 알려진 대표적인 Freak wave이다. 파형의 계 측은 플랫폼 수면 아래로 레이저와 센서가 설치되어 있어 수면 과 센서 사이의 순간 거리를 측정한다. 파랑의 계측주파수는 $2.1333 \mathrm{~Hz}$ 로, 계측주파수는 최대파고에 크기에 미치는 영향은 크 지 않다고 볼 수 있다(Kim, 2013b). 한 개의 파랑계측 자료는 20 분 동안 계측된 수면의 높이가 저장되어 있으면 한 개당 2,560 개 의 데이터가 포함된다. 이 논문에서는 1995년 1월에 발생한 총 48 개의 파랑자료를 분석하였다. 각 파랑자료는 최대파고가 $8 \mathrm{~m}$ 이상인 파도가 포함되어있다. Table 1 에 표시한 파랑자료의 구분 은 'D01_1520'형태로 표시하였고 시간별로 1 48까지 ID 일련번 호를 부여하였다. 여기서 처음 두개 숫자는 날짜를 나타내며 마 지막 4개의 숫자는 계측 시간을 나타낸다. 따라서 'D01_1520'은 1 일 15 시 20 분에 계측된 파랑자료를 의미한다.

사용한 48 개의 파랑자료 중 3 개의 파랑자료에 Freak wave가

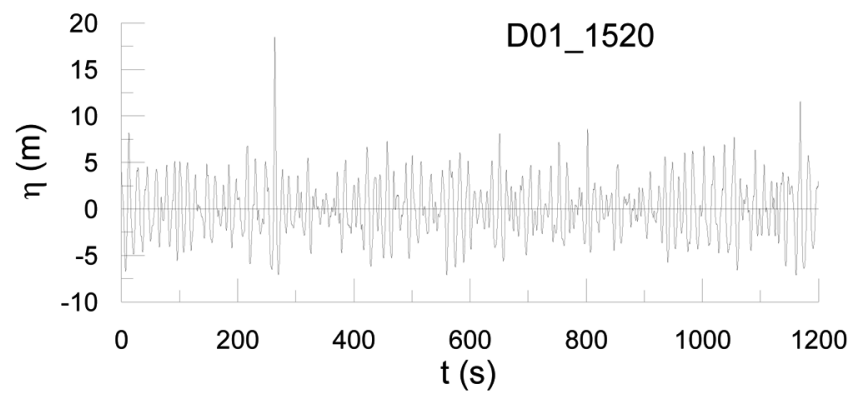

Fig. 1 Time series of surface elevation of D01_1520

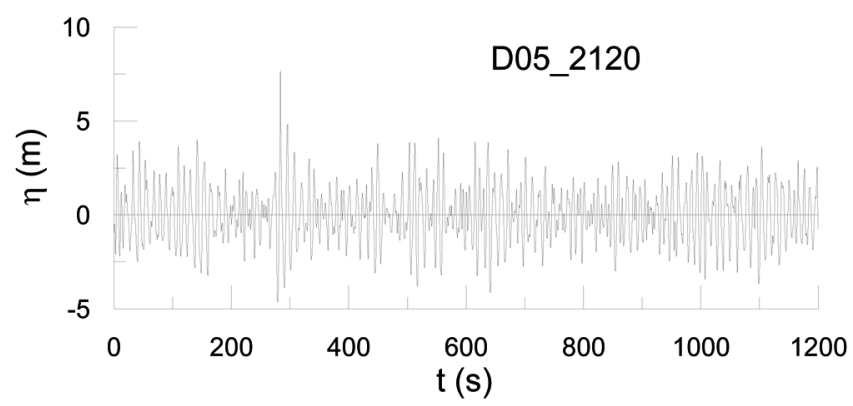

Fig. 2 Time series of surface elevation of D05_2120

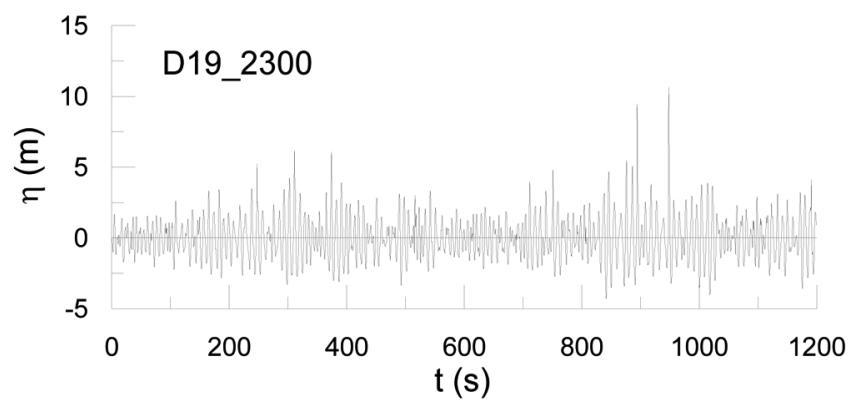

Fig. 3 Time series of surface elevation of D19_2300
포함되어 있다. Fig. 1에 Freak wave가 포함되어 있는 D01 1520, D05_2120, D19_2300 3개의 파형의 시계열 자료를 표시하였다. Fig. 1에는 280 초 근방에서 평균파고보다 매우 큰 파고 $20 \mathrm{~m}$ 가 넘는 freak wave가 발생하였고, 이 파도는 'New Year Wave'라 불리고 있다. Fig. 2에서 280초 근방에서 파고가 $10 \mathrm{~m}$ 이상의 Freak wave, Fig. 3에서 950초 근방에서 파고 $10 \mathrm{~m}$ 이상의 Freak wave가 발생한 것을 볼 수 있다. Fig. 3 에서는 짧은 시간 안에 2 개의 큰 파도가 발생한 것을 볼 수 있다.

\section{3. 파랑자료의 통계적 특성}

주어진 수면의 시계열자료에서 파형의 분산, 비대칭도 및 첨 도 등 파형과 관련된 통계치를 계산하였다. 두 개의 연속적인 영점상향지점으로 개별 파랑을 구분하였고 이에 따른 파고 및 주기에 관련된 각종 통계치를 계산하였다. 그리고 FFT(Fast fourier transform)를 이용하여 파랑스펙트럼을 계산하였고 최종 적으로 $0.01 \mathrm{~Hz}$ 의 주파수 해상도(Frequency resolution)을 가지도 록 평균한 파랑스펙트럼을 사용하여 파랑스펙트럼과 관련된 통 계치를 계산하였다. Table 1에 48개 파랑자료에 대한 각종 통계 결과를 표시하였다. Table 2에는 이상 지수(Abnormality index, $\mathrm{AI}$ )가 2.0 이상인 Freak wave가 포함된 자료의 계산 결과를 따 로 표시하였고 각 기호에 대한 설명이 포함되어 있다.

Table 3에는 각 변수에 대한 사분위(Quartile) 값을 표시했고, Fig. 4에서는 각 변수에 대해서 박스플롯을 작성하였다. Fig. 4에 서는 값이 비슷한 변수끼리 모아서 표시를 하였고 종축은 각 변 수의 값을 나타낸다. 박스 안의 진한 선은 $50 \%$ 박스의 위 부분 은 $75 \%$, 아래 부분은 $25 \%$ 를 나타내며, 위 아래의 표시된 선은 사분위 변위의 1.5 배 되는 지점을 표시하고 있다. 각 변수별로 사분위변위(Interquartile range, IQR)의 1.5 배를 벗어난 이상치 (Outlier)가 존재 한다. 특히 최대파의 경우는 최소가 $8.14 \mathrm{~m}$ 이고 최대가 $25.58 \mathrm{~m}$ 가 되어, 이상치가 사분위 변위를 초과하는 정도가 가장 심한 것을 볼 수 있다. 이에 반해서 유의파첨도(Significant steepness)와 대역폭(Bandwidth parameter)는 이상치가 가장 적게 나타난다. 이것은 파랑자료가 최대파의 크기가 $8 \mathrm{~m}$ 가 넘는 일정 이상의 거친 해상상태에서 측정한 자료인 영향으로 생각된다.

Freak wave가 포함된 파랑자료의 파형분포는 정규분포보다는 비정규 분포함수인 Gram-Chalier 분포함수로 잘 표시할 수 있다 (Kim, 2013a). Fig. 5에는 파형분포에 대한 정규분포 분위수 대 조도(Q-Q plot)를 표시하였다. 수평축은 파형의 높이를 표준화 한 값을 나타낸다. 여기서 직선은 완전한 정규분포일 경우를 나 타낸다. 이 그림에서 중간 분위에서는 정규분포와 일치를 하나, 수면이 높은 곳과 낮은 곳에서 실제자료가 더 높은 쪽에 위치 하는 것을 볼 수 있다. 이것은 파고가 커질수록 분포가 정규분 포에서 벗어나며, 파정과 파저 부근의 파형의 발생 확률이 더 높게 나타나는 것을 의미한다.

Fig. 6에 freak wave가 발생한 파랑자료를 분해능 $0.01 \mathrm{~Hz}$ 의 주 파수해상도로 계산한 스펙트럼과, 유의파고와 영점상향통과 주 기를 2개의 파라미터로 가지는 Modified Pierson-Moskowitz 스펙 트럼과 JONSWAP(Joint North Sea wave project) 스펙트럼과 비 교를 하였다. 파랑스펙트럼을 계산할 때 JONSWAP 스펙트럼과 Modified Pierson-Moskowitz 스펙트럼의 면적이 같도록 설정하였 
Table 1 Draupner wave data statistics

\begin{tabular}{|c|c|c|c|c|c|c|c|c|c|c|c|c|c|c|c|c|}
\hline ID & Data & $\sigma$ & $\gamma$ & $\kappa$ & $H_{0}$ & $T_{0}$ & $H_{1 / 3}$ & $H_{\mathrm{s}}$ & $H_{\max }$ & $T_{H_{\max }}$ & $H_{s}$ & $T_{z}$ & $T_{p}$ & $\nu$ & $S_{s}$ & $\gamma_{J}$ \\
\hline 01 & D01_0620 & 1.922 & 0.102 & 2.884 & 4.80 & 9.59 & 7.39 & 5.33 & 12.37 & 10.84 & 7.69 & 9.10 & 11.76 & 0.404 & 0.060 & 2.40 \\
\hline 02 & D01_0920 & 1.943 & 0.196 & 3.553 & 4.65 & 9.20 & 7.64 & 5.34 & 3.63 & 11.75 & 7.76 & 8.81 & 13.33 & 0.434 & 0.064 & 1.28 \\
\hline 03 & D01_1420 & 2.790 & 0.253 & 3.132 & 7.10 & 11.88 & 10.85 & 7.85 & 16.49 & 15.05 & 11.14 & 10.81 & 15.38 & 0.450 & 0.061 & 1.57 \\
\hline 04 & D01_1520 & 2.983 & 0.413 & 4.062 & 7.12 & 11.28 & 11.58 & 8.20 & 25.58 & 12.50 & 11.92 & 10.81 & 15.38 & 0.475 & 0.065 & 1.88 \\
\hline 05 & D01_1620 & 3.020 & 0.217 & 3.293 & 7.57 & 12.58 & 12.20 & 8.55 & 20.46 & 14.29 & 12.04 & 11.53 & 18.18 & 0.461 & 0.058 & 0.76 \\
\hline 06 & D01_1720 & 2.849 & 0.134 & 2.929 & 6.79 & 11.20 & 11.10 & 7.70 & 15.74 & 17.80 & 11.37 & 10.90 & 15.38 & 0.488 & 0.061 & 1.66 \\
\hline 07 & D01_1820 & 2.991 & 0.233 & 2.976 & 7.83 & 12.70 & 11.86 & 8.70 & 20.18 & 15.52 & 11.96 & 11.18 & 15.38 & 0.481 & 0.061 & 1.89 \\
\hline 08 & D02_0620 & 1.730 & 0.162 & 2.912 & 4.33 & 9.43 & 6.64 & 4.81 & 10.52 & 9.03 & 6.88 & 8.83 & 11.76 & 0.414 & 0.057 & 1.81 \\
\hline 09 & D04_2340 & 1.546 & 0.226 & 2.999 & 3.70 & 7.91 & 5.95 & 4.20 & 9.82 & 10.17 & 6.15 & 7.82 & 10.53 & 0.393 & 0.064 & 2.39 \\
\hline 10 & D05_0020 & 1.666 & 0.136 & 2.568 & 4.34 & 8.88 & 6.33 & 4.71 & 8.80 & 8.74 & 6.62 & 8.27 & 11.76 & 0.384 & 0.062 & 1.64 \\
\hline 11 & D05_0140 & 1.554 & 0.087 & 2.820 & 3.83 & 8.31 & 5.89 & 4.27 & 8.85 & 11.27 & 6.19 & 7.83 & 10.53 & 0.428 & 0.065 & 2.43 \\
\hline 12 & D05_0320 & 1.522 & 0.177 & 3.067 & 3.69 & 8.24 & 6.08 & 4.21 & 8.17 & 9.45 & 6.06 & 7.97 & 10.53 & 0.383 & 0.061 & 2.31 \\
\hline 13 & D05_0620 & 1.783 & 0.197 & 2.829 & 4.47 & 8.75 & 6.91 & 4.94 & 10.30 & 10.36 & 7.12 & 8.40 & 11.76 & 0.403 & 0.065 & 1.98 \\
\hline 14 & D05_0920 & 1.788 & 0.138 & 3.056 & 4.51 & 8.94 & 6.79 & 4.98 & 12.41 & 10.15 & 7.14 & 8.06 & 11.76 & 0.480 & 0.070 & 1.99 \\
\hline 15 & D05_1220 & 1.965 & 0.147 & 2.863 & 4.92 & 9.51 & 7.60 & 5.48 & 12.16 & 9.08 & 7.82 & 8.46 & 11.76 & 0.490 & 0.070 & 2.50 \\
\hline 16 & D05_1820 & 1.832 & 0.119 & 2.892 & 4.43 & 9.00 & 7.15 & 5.01 & 9.99 & 10.05 & 7.31 & 8.62 & 11.76 & 0.428 & 0.063 & 2.11 \\
\hline 17 & D05_2120 & 1.512 & 0.144 & 3.122 & 3.68 & 8.55 & 5.73 & 4.13 & 11.59 & 11.44 & 6.01 & 8.15 & 11.76 & 0.435 & 0.058 & 1.27 \\
\hline 18 & D05_2220 & 1.586 & 0.085 & 2.797 & 3.89 & 8.75 & 6.21 & 4.36 & 9.17 & 10.01 & 6.32 & 8.49 & 11.76 & 0.424 & 0.056 & 1.45 \\
\hline 19 & D09_1920 & 1.576 & 0.050 & 3.160 & 3.96 & 8.57 & 6.17 & 4.41 & 10.66 & 9.79 & 6.28 & 7.87 & 9.52 & 0.399 & 0.065 & 3.98 \\
\hline 20 & D09_2120 & 1.571 & 0.079 & 2.945 & 3.76 & 8.22 & 6.09 & 4.27 & 9.94 & 8.62 & 6.24 & 8.09 & 10.53 & 0.421 & 0.061 & 2.48 \\
\hline 21 & D09_2240 & 1.738 & 0.226 & 3.702 & 4.08 & 8.37 & 6.91 & 4.74 & 11.02 & 10.40 & 6.95 & 8.34 & 10.53 & 0.420 & 0.064 & 3.20 \\
\hline 22 & D10_0020 & 1.982 & 0.180 & 2.706 & 5.04 & 9.13 & 7.57 & 5.54 & 10.26 & 10.09 & 7.91 & 8.41 & 11.76 & 0.451 & 0.072 & 2.56 \\
\hline 23 & D10_0320 & 2.000 & 0.073 & 2.645 & 4.93 & 9.41 & 7.74 & 5.50 & 10.28 & 11.92 & 7.99 & 8.84 & 10.53 & 0.417 & 0.066 & 4.35 \\
\hline 24 & D10_0620 & 1.865 & 0.163 & 2.981 & 4.79 & 9.47 & 7.09 & 5.26 & 12.21 & 9.49 & 7.43 & 8.47 & 11.76 & 0.452 & 0.066 & 2.20 \\
\hline 25 & D10_0920 & 1.696 & 0.120 & 2.872 & 4.15 & 9.04 & 6.53 & 4.62 & 10.02 & 11.32 & 6.76 & 8.75 & 11.76 & 0.414 & 0.057 & 1.73 \\
\hline 26 & D11_1540 & 1.539 & 0.136 & 2.753 & 3.75 & 8.70 & 5.79 & 4.17 & 8.24 & 9.22 & 6.13 & 8.20 & 11.76 & 0.441 & 0.058 & 1.33 \\
\hline 27 & D11_1620 & 1.552 & 0.047 & 2.984 & 3.59 & 8.17 & 5.94 & 4.11 & 8.97 & 10.86 & 6.18 & 8.29 & 11.76 & 0.438 & 0.058 & 1.36 \\
\hline 28 & D11_1820 & 1.694 & 0.137 & 3.049 & 4.22 & 8.93 & 6.71 & 4.72 & 10.74 & 11.53 & 6.75 & 8.37 & 10.53 & 0.435 & 0.062 & 2.99 \\
\hline 29 & D11_2120 & 1.854 & 0.145 & 2.801 & 4.64 & 9.20 & 7.04 & 5.14 & 9.79 & 11.07 & 7.38 & 8.66 & 11.76 & 0.438 & 0.063 & 2.17 \\
\hline 30 & D12_0020 & 1.884 & 0.111 & 2.902 & 4.81 & 10.20 & 7.36 & 5.32 & 10.87 & 11.65 & 7.52 & 8.90 & 13.33 & 0.504 & 0.061 & 1.18 \\
\hline 31 & D12_0320 & 1.566 & 0.112 & 2.772 & 3.94 & 8.97 & 5.90 & 4.30 & 9.04 & 10.53 & 6.23 & 8.12 & 11.76 & 0.480 & 0.060 & 1.40 \\
\hline 32 & D16_1340 & 1.554 & 0.017 & 2.841 & 3.77 & 8.35 & 5.88 & 4.24 & 9.41 & 10.05 & 6.17 & 8.12 & 10.53 & 0.403 & 0.060 & 2.41 \\
\hline 33 & D16_1500 & 1.539 & 0.185 & 3.193 & 3.68 & 8.33 & 5.97 & 4.18 & 8.78 & 8.88 & 6.15 & 8.03 & 10.53 & 0.413 & 0.061 & 2.39 \\
\hline 34 & D16_1520 & 1.552 & 0.214 & 3.365 & 3.76 & 8.06 & 5.91 & 4.23 & 11.10 & 10.26 & 6.17 & 7.87 & 10.53 & 0.413 & 0.064 & 2.41 \\
\hline 35 & D16_1620 & 1.641 & 0.123 & 3.015 & 4.02 & 8.13 & 6.38 & 4.52 & 9.63 & 9.66 & 6.56 & 7.84 & 10.53 & 0.406 & 0.068 & 2.79 \\
\hline 36 & D16_1820 & 1.565 & 0.237 & 2.846 & 3.85 & 8.16 & 5.97 & 4.28 & 8.92 & 8.30 & 6.24 & 7.83 & 10.53 & 0.422 & 0.065 & 2.47 \\
\hline 37 & D16_2140 & 1.514 & 0.143 & 2.989 & 3.66 & 8.26 & 5.96 & 4.13 & 9.21 & 9.12 & 6.04 & 8.09 & 11.76 & 0.427 & 0.059 & 1.28 \\
\hline 38 & D16_2220 & 1.557 & -0.103 & 2.613 & 3.86 & 8.42 & 5.96 & 4.27 & 8.14 & 10.24 & 6.18 & 8.08 & 11.76 & 0.436 & 0.061 & 1.37 \\
\hline 39 & D17_2240 & 1.791 & 0.221 & 3.085 & 4.33 & 8.59 & 6.85 & 4.90 & 12.01 & 9.78 & 7.13 & 8.11 & 10.53 & 0.403 & 0.069 & 3.39 \\
\hline 40 & D18_0320 & 1.947 & 0.117 & 2.761 & 4.92 & 9.50 & 7.61 & 5.46 & 11.31 & 9.71 & 7.78 & 8.88 & 11.76 & 0.416 & 0.063 & 2.46 \\
\hline 41 & D18_0620 & 1.692 & 0.134 & 2.884 & 4.01 & 8.07 & 6.41 & 4.52 & 8.75 & 10.19 & 6.74 & 8.04 & 11.76 & 0.433 & 0.067 & 1.72 \\
\hline 42 & D18_0700 & 1.777 & 0.142 & 2.928 & 4.30 & 8.53 & 6.87 & 4.86 & 10.09 & 10.03 & 7.09 & 8.25 & 10.53 & 0.428 & 0.067 & 3.34 \\
\hline 43 & D18_0840 & 1.587 & 0.316 & 3.210 & 3.88 & 8.36 & 6.14 & 4.36 & 9.60 & 10.33 & 6.33 & 7.92 & 11.76 & 0.439 & 0.065 & 1.46 \\
\hline 44 & D18_1000 & 1.593 & 0.122 & 2.685 & 4.10 & 8.72 & 6.24 & 4.50 & 8.51 & 8.10 & 6.35 & 8.00 & 11.76 & 0.412 & 0.064 & 1.47 \\
\hline 45 & D18_1300 & 1.523 & 0.110 & 2.826 & 3.82 & 8.68 & 5.93 & 4.27 & 9.23 & 9.39 & 6.06 & 8.19 & 10.53 & 0.376 & 0.058 & 2.31 \\
\hline 46 & D19_2300 & 1.527 & 0.617 & 5.286 & 3.69 & 7.19 & 6.10 & 4.27 & 13.87 & 7.98 & 6.08 & 6.43 & 9.52 & 0.546 & 0.094 & 3.71 \\
\hline 47 & D20_0020 & 1.811 & 0.154 & 2.778 & 4.59 & 8.68 & 6.96 & 5.06 & 9.60 & 9.18 & 7.19 & 8.18 & 9.52 & 0.351 & 0.069 & 5.31 \\
\hline 48 & D20_0320 & 1.907 & 0.241 & 2.995 & 4.64 & 8.65 & 7.37 & 5.22 & 11.06 & 11.87 & 7.59 & 8.23 & 10.53 & 0.456 & 0.072 & 3.89 \\
\hline
\end{tabular}


Table 2 Summary of wave statistics from data containing freak wave

\begin{tabular}{llccc}
\hline \hline \multicolumn{1}{c}{ Description } & D01_1520 & D05_2120 & D19_2300 \\
\hline$\sigma_{\eta}$ & RMS of wave elevation & 2.98 & 1.51 & 1.53 \\
$\gamma$ & Skewness of wave elevation & 0.41 & 0.14 & 0.62 \\
$\kappa$ & Kurtosis of wave elevation & 4.06 & 3.12 & 5.29 \\
$H_{0}$ & Average wave height & 7.12 & 3.68 & 3.69 \\
$T_{0}$ & Average zero up-crossing period (time domain) & 11.28 & 8.55 & 7.19 \\
$H_{1 / 3}$ & Significant wave height (time domain) & 11.58 & 5.73 & 6.10 \\
$H_{\mathrm{S}}$ & RMS of wave height & 8.20 & 4.13 & 4.27 \\
$H_{\max }$ & Maximum wave height & 25.58 & 11.59 & 13.87 \\
$T_{H_{\max }}$ & Wave period of maximum wave height & 12.50 & 11.44 & 7.98 \\
$H_{s}$ & Significant wave height (frequency domain) & 11.92 & 6.01 & 6.08 \\
$T_{z}$ & Average zero up-crossing period (frequency domain) & 10.81 & 8.15 & 6.43 \\
$T_{p}$ & Peak period of wave spectrum & 15.38 & 11.76 & 9.52 \\
$f_{p}$ & Peak frequency of wave spectrum & 0.065 & 0.085 & 0.105 \\
$\nu$ & Bandwidth of wave spectrum & 0.48 & 0.44 & 0.55 \\
$S_{s}$ & Significant steepness & 0.07 & 0.06 & 0.09 \\
$\gamma_{J}$ & Peak enhancement factor (JONSWAP spectrum) & 1.88 & 1.27 & 3.71 \\
$A I$ & Abnormality Index $=H_{\max } / H_{1 / 3}$ & 2.21 & 2.02 & 2.27 \\
\hline
\end{tabular}

Table 3 Quartiles of variables

\begin{tabular}{|c|c|c|c|c|c|}
\hline & Min & $25 \%$ & $50 \%$ & $75 \%$ & Max \\
\hline$\sigma_{\eta}$ & 1.512 & 1.556 & 1.695 & 1.890 & 3.020 \\
\hline$\gamma$ & -0.103 & 0.116 & 0.143 & 0.201 & 0.617 \\
\hline$\kappa$ & 2.568 & 2.825 & 2.929 & 3.072 & 5.286 \\
\hline$H_{0}$ & 3.590 & 3.828 & 4.185 & 4.685 & 7.830 \\
\hline$T_{0}$ & 7.190 & 8.345 & 8.710 & 9.253 & 12.700 \\
\hline$H_{1 / 3}$ & 5.730 & 5.970 & 6.585 & 7.363 & 12.200 \\
\hline$H_{\mathrm{s}}$ & 4.110 & 4.270 & 4.715 & 5.275 & 8.700 \\
\hline$H_{\text {max }}$ & 8.140 & 9.200 & 10.175 & 11.695 & 25.580 \\
\hline$T_{H_{\max }}$ & 7.980 & 9.435 & 10.160 & 11.283 & 17.800 \\
\hline$H_{s}$ & 6.010 & 6.188 & 6.755 & 7.538 & 12.040 \\
\hline$T_{z}$ & 6.430 & 8.055 & 8.240 & 8.683 & 11.530 \\
\hline$T_{p}$ & 9.520 & 10.530 & 11.760 & 11.760 & 18.180 \\
\hline$\nu$ & 0.351 & 0.413 & 0.428 & 0.450 & 0.546 \\
\hline$S_{s}$ & 0.056 & 0.061 & 0.063 & 0.065 & 0.094 \\
\hline$\gamma_{J}$ & 0.760 & 1.545 & 2.185 & 2.485 & 5.310 \\
\hline$A I$ & 1.330 & 1.458 & 1.525 & 1.655 & 2.270 \\
\hline
\end{tabular}
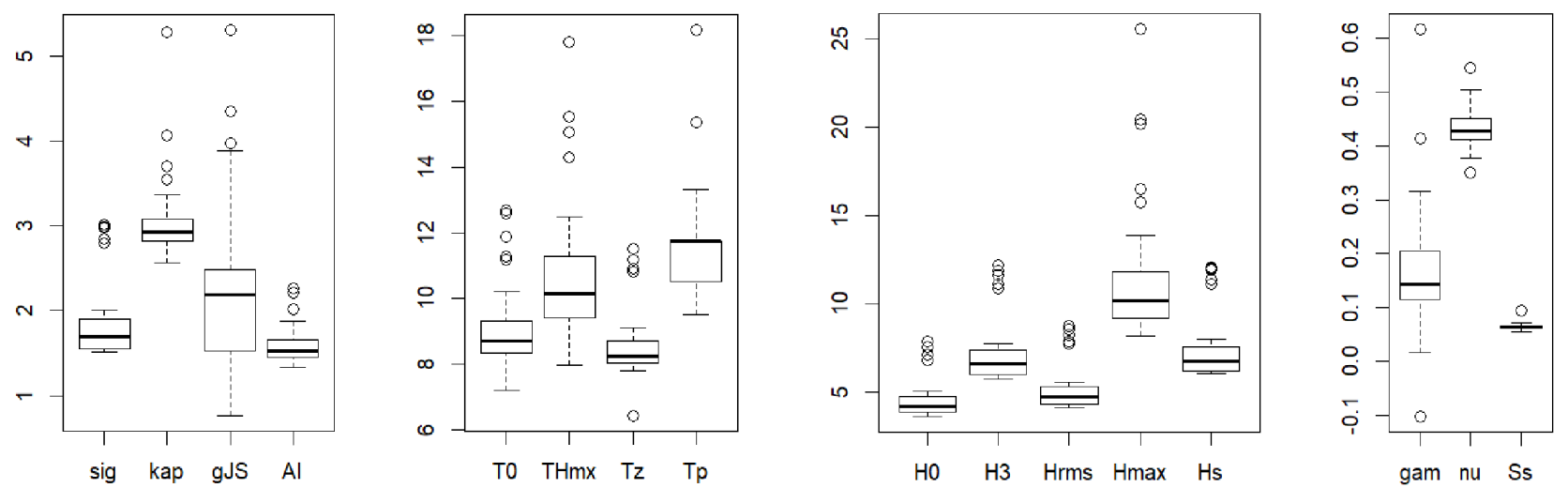

Fig. 4 Boxplots of wave data 

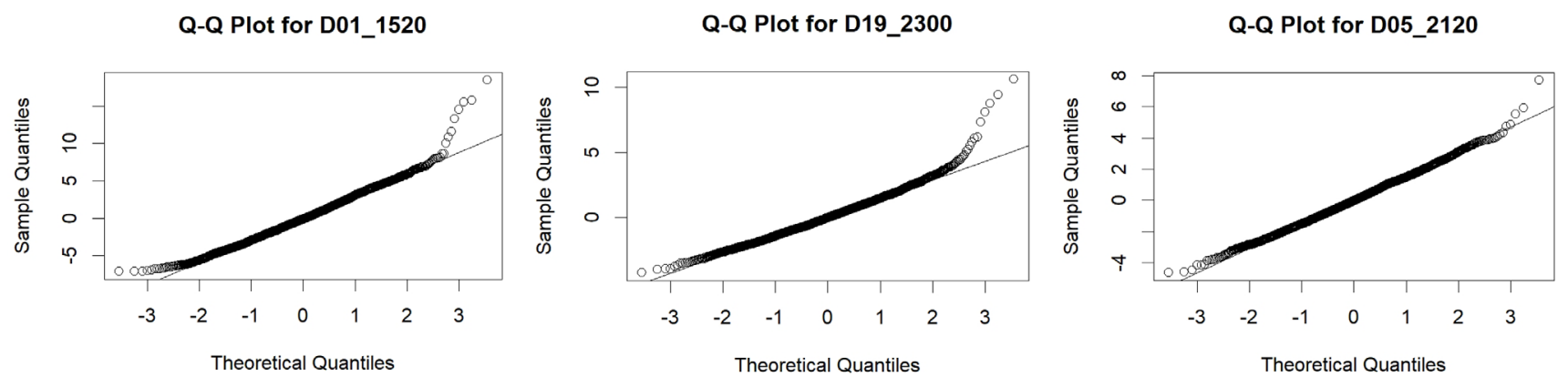

Fig. 5 Q-Q plot of wave elevation distribution from data containing freak wave
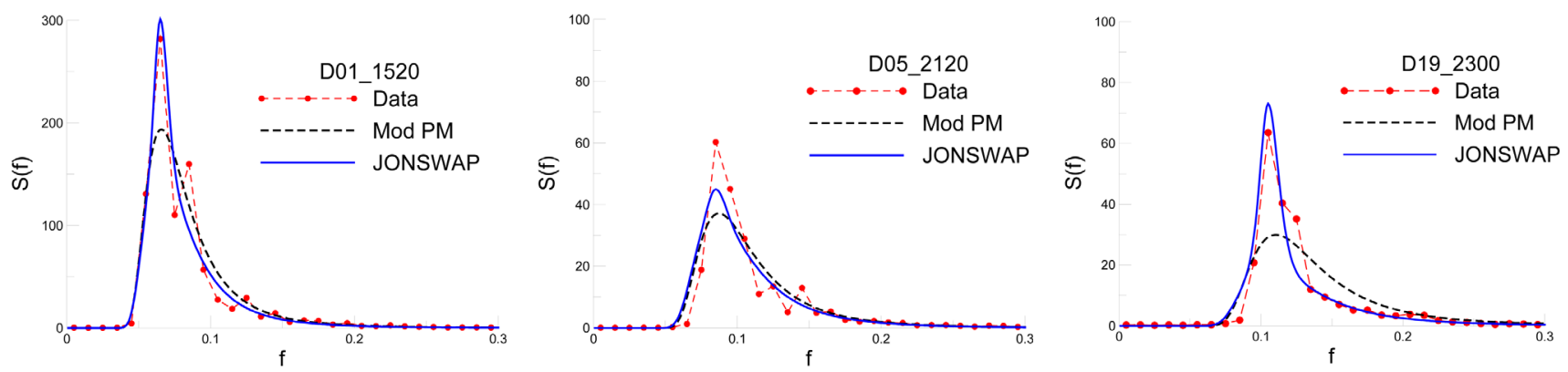

Fig. 6 Wave spectrums from data containing freak wave

고, Peak enhancement facto는 각 $1.88,1.27$, 그리고 2.27 을 가진 다. JONSWAP 스펙트럼이 Modified Pierson-Moskowitz 스펙트럼 보다 파랑자료와 더 일치하는 것을 볼 수 있다.

\section{4. 통계변수와 이상지수와의 관계}

Table 4 에서는 15 개의 변수와 이상지수와의 상관관계를 표시 하였다. 이상지수와 상관관계가 높은 5 개 변수는 큰 순서부터 첨도(Kurtosis, $\kappa)$, 비대칭도(Skewness, $\gamma)$, 최대파고 $\left(H_{\max }\right)$, 대역 폭(Bandwidth parameter, $\nu$ ), 유의파첨도(Significant steepness, $S_{s}$ )
이다. Fig. 7 에서는 이상지수와 상관관계가 높은 상위 5 개 변수 에 대한 Pair plot을 표시하였다. 이 그림에서 첨도, 비대칭도, 최 대파고와 이상지수와는 서로 상관관계가 있음을 볼 수 있다. Fig. 8 에서는 각종 파고들의 Pair plot을 표시하였다. 최대파고를 제외한 각종 파고들은 서로 상관관계가 높게 나타나는 것을 볼 수 있다. Fig. 9에서는 각종 파주기에 대한 Pair plot을 표시하였 다. 이 그림에서 스펙트럼의 첨두주파수(Peak frequency, $\left.T_{p}\right)$ 는 주파수분해능 $0.01 \mathrm{~Hz}$ 로 평균한 값을 사용했기 때문에 분포가 Categorical data처럼 보이고 있다. 이점을 감안하면 각종 파주기 들은 서로 상관관계가 높게 나타나고 있다.

Table 4 Correlations of variables

\begin{tabular}{|c|c|c|c|c|c|c|c|c|c|c|c|c|c|c|c|}
\hline$\sigma$ & 0.27 & 0.13 & 0.99 & 0.94 & 1.00 & 1.00 & 0.89 & 0.81 & 1.00 & 0.94 & 0.86 & 0.40 & -0.06 & -0.15 & 0.16 \\
\hline 0.27 & $\gamma$ & 0.81 & 0.25 & 0.09 & 0.29 & 0.28 & 0.50 & 0.04 & 0.27 & 0.05 & 0.13 & 0.42 & 0.62 & 0.15 & 0.60 \\
\hline 0.13 & 0.81 & $\kappa$ & 0.09 & -0.05 & 0.16 & 0.13 & 0.47 & 0.01 & 0.14 & -0.07 & 0.04 & 0.47 & 0.60 & 0.15 & 0.78 \\
\hline 0.99 & 0.25 & 0.09 & $H_{0}$ & 0.96 & 0.99 & 1.00 & 0.87 & 0.79 & 0.99 & 0.93 & 0.85 & 0.39 & -0.06 & -0.15 & 0.14 \\
\hline 0.94 & 0.09 & -0.05 & 0.96 & $T_{0}$ & 0.93 & 0.95 & 0.79 & 0.78 & 0.94 & 0.96 & 0.89 & 0.36 & -0.29 & -0.30 & 0.07 \\
\hline 1.00 & 0.29 & 0.16 & 0.99 & 0.93 & $H_{1 / 3}$ & 1.00 & 0.89 & 0.80 & 1.00 & 0.94 & 0.86 & 0.40 & -0.05 & -0.15 & 0.17 \\
\hline 1.00 & 0.28 & 0.13 & 1.00 & 0.95 & 1.00 & $H_{\mathrm{s}}$ & 0.89 & 0.79 & 1.00 & 0.94 & 0.85 & 0.40 & -0.05 & -0.15 & 0.17 \\
\hline 0.89 & 0.50 & 0.47 & 0.87 & 0.79 & 0.89 & 0.89 & $H_{\max }$ & 0.64 & 0.89 & 0.78 & 0.75 & 0.48 & 0.09 & -0.13 & 0.58 \\
\hline 0.81 & 0.04 & 0.01 & 0.79 & 0.78 & 0.80 & 0.79 & 0.64 & $T_{H_{\max }}$ & 0.81 & 0.83 & 0.75 & 0.36 & -0.24 & -0.23 & 0.05 \\
\hline 1.00 & 0.27 & 0.14 & 0.99 & 0.94 & 1.00 & 1.00 & 0.89 & 0.81 & $H_{s}$ & 0.94 & 0.86 & 0.40 & -0.06 & -0.15 & 0.17 \\
\hline 0.94 & 0.05 & -0.07 & 0.93 & 0.96 & 0.94 & 0.94 & 0.78 & 0.83 & 0.94 & $T_{z}$ & 0.90 & 0.25 & -0.39 & -0.33 & 0.03 \\
\hline 0.86 & 0.13 & 0.04 & 0.85 & 0.89 & 0.86 & 0.85 & 0.75 & 0.75 & 0.86 & 0.90 & $T_{p}$ & 0.44 & -0.33 & -0.62 & 0.11 \\
\hline 0.40 & 0.42 & 0.47 & 0.39 & 0.36 & 0.40 & 0.40 & 0.48 & 0.36 & 0.40 & 0.25 & 0.44 & $\nu$ & 0.39 & -0.26 & 0.40 \\
\hline-0.06 & 0.62 & 0.60 & -0.06 & -0.29 & -0.05 & -0.05 & 0.09 & -0.24 & -0.06 & -0.39 & -0.33 & 0.39 & $S_{s}$ & 0.55 & 0.36 \\
\hline-0.15 & 0.15 & 0.15 & -0.15 & -0.30 & -0.15 & -0.15 & -0.13 & -0.23 & -0.15 & -0.33 & -0.62 & -0.26 & 0.55 & $\gamma_{J}$ & 0.02 \\
\hline 0.16 & 0.60 & 0.78 & 0.14 & 0.07 & 0.17 & 0.17 & 0.58 & 0.05 & 0.17 & 0.03 & 0.11 & 0.40 & 0.36 & 0.02 & $A I$ \\
\hline
\end{tabular}




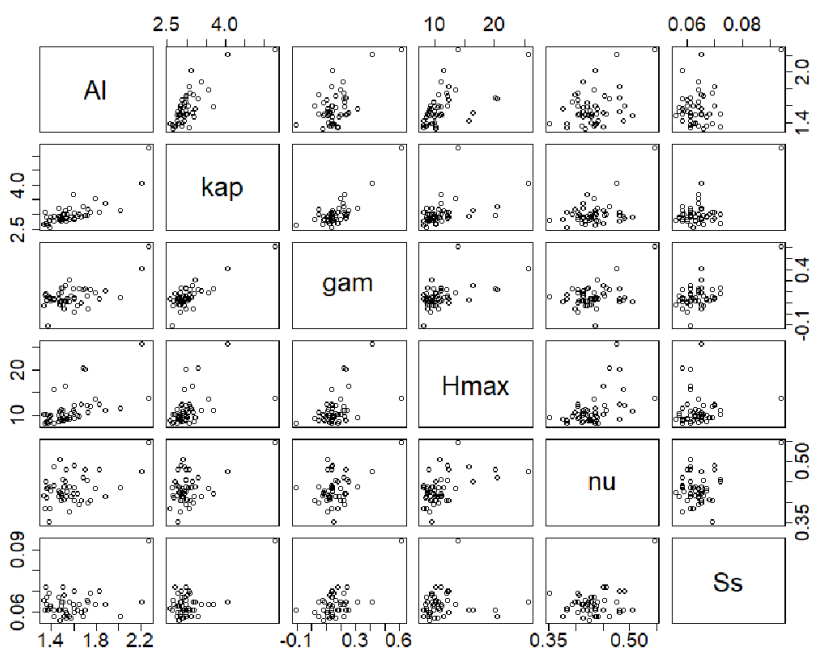

Fig. 7 Pair plots of AI and 5 highly correlated variables with AI

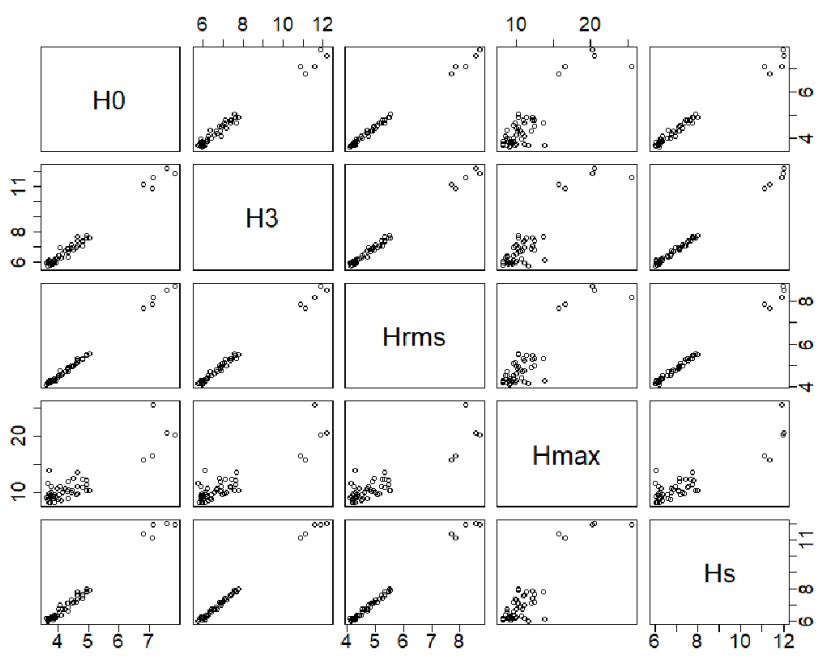

Fig. 8 Pair plots of various wave heights

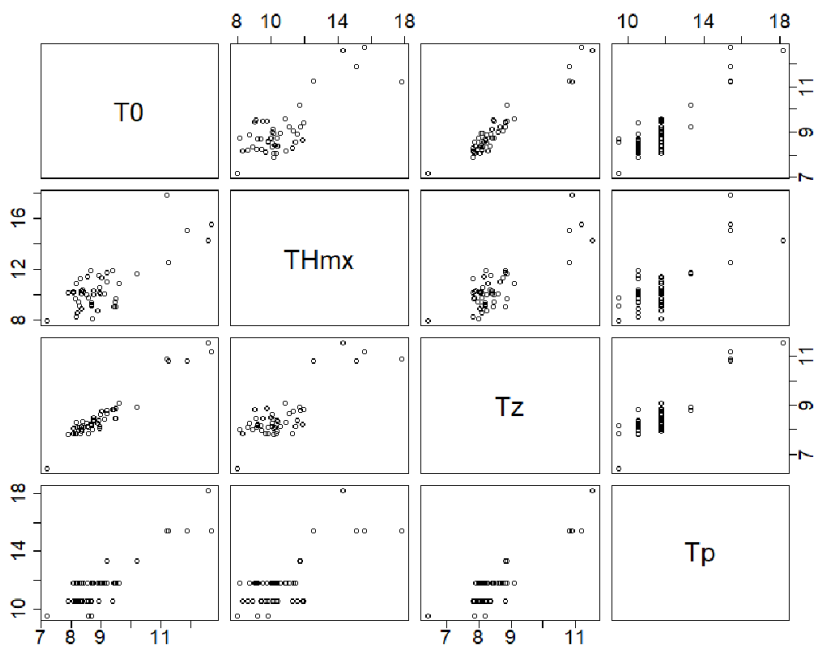

Fig. 9 Pair plots of various wave periods

변수들과 이상지수와의 관계를 심층적으로 분석하기 위해서 주축해석(PCA, Principal coordinate analysis)방법을 사용하기로 한다. 이것은 차원이 높은 데이터를 차원이 낮은 2 차원적 표현

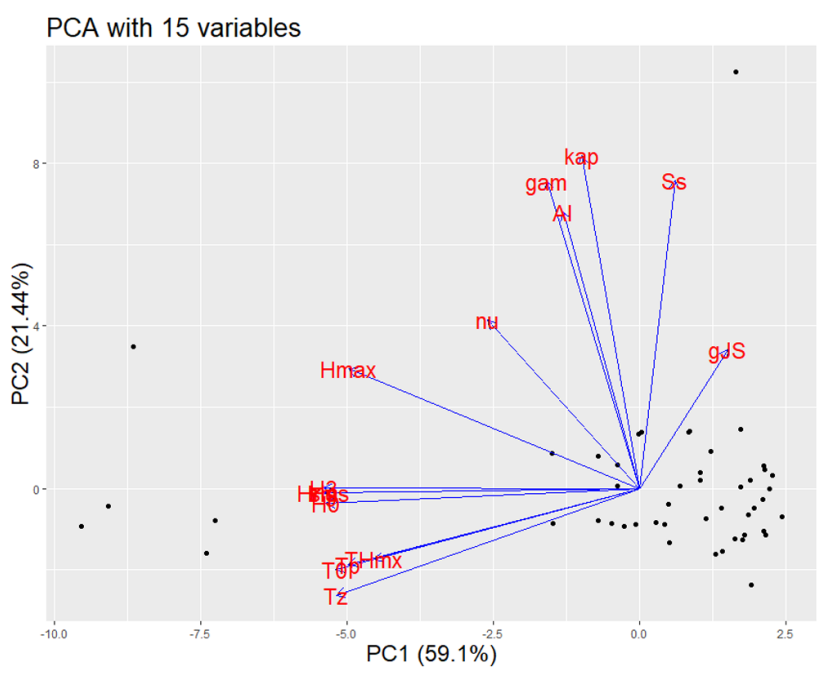

Fig. 10 PCA with 15 variables

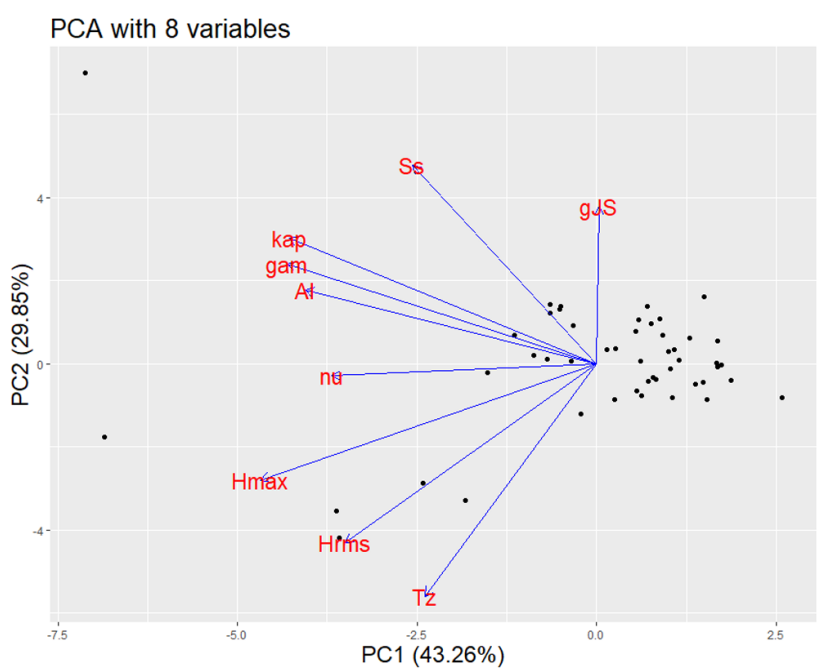

Fig. 11 PCA with 8 variables

을 하고, 1 번째 주축은 데이터가 사상변환 행렬의 가장 크기가 큰 고유벡터에 해당하는 고유벡터 방향이 된다. 따라서 이 축은 데이터의 변화가 가장 잘 감지되는 축이 된다. Fig. 10에서는 처 음 2 개의 주축(Principal coordinate)상에서 48 개의 데이터를 점으 로 표시하였고, 15 개의 변수와 이상지수의 변화 방향과 크기를 나타내는 고유벡터를 표시하였다. 주축해석에는 통계해석 프로 그램 R(James et al, 2015)을 사용하였다. 1번 주축에서 전체 변 화량 중 $59.1 \%$ 의 변화량을 2 번 주축에서 $21.44 \%$ 의 변화량을 감 지할 수 있으며, 처음 2 개의 주축에서 $80.5 \%$ 의 변화량을 감지할 수 있다. 15 개의 변수 중 파고와 관련된 변수는 최대파고를 제 외하고는 대부분 비슷한 방향의 고유벡터를 가지고 있으며, 파 주기와 관련된 변수들은 서로 비슷한 방향의 고유벡터를 가지 고 있는 것을 볼 수 있다. 이상지수의 변화의 방향은 첨도 $\kappa$ 와 비대칭도 $\gamma$ 변화와 가장 비슷한 방향의 벡터를 가지는 것을 볼 수 있다. 유의파첨도와 대역폭이 그 다음으로 이상지수의 방향 과 비슷한 방향을 보이고 있다. 최대파고는 이상지수의 상관관 계가 파첨도와 대역폭보다는 높지만 변화 방향은 덜 일치하는 것을 볼 수 있다. Fig. 11 에서는 8 개의 변수와 이상지수의 변화 
를 나타내는 고유벡터를 표시하였다. 15 개의 변수를 사용한 것 과 방향이 약간 다르지만 전체적으로 Fig. 10과 비슷한 결과를 보이고 있다. 상관계수와 주축해석을 종합하면 이상지수의 예 측에는 첨도 $\kappa$ 와 비대칭도 $\gamma$ 가 가장 중요한 변수임을 확인 할 수 있다.

\section{5. 결 론}

본 논문에서는 Draupner platform에서 계측된 48개의 파랑자료 를 분석하고, 주요 15 개 변수들의 통계치를 계산하여 제시하였 다. 그리고 각 변수들의 사분위 값, 박스플롯, 상관계수와 Pair plot을 제시하였다. 최대파고는 이상치(Outlier)가 사분위변위을 초과하는 정도가 가장 심한 것을 볼 수 있었다. 파형의 분포는 정규분포에서 벗어나는 것을 볼 수 있었으며, JONSWAP 스펙 트럼이 파랑계측자료와 잘 일치하는 것을 볼 수 있었다. Freak wave를 정의하는 이상지수와 15 개의 변수와의 연관성을 살펴보 았다. 파형의 첨도와 비대칭도가 이상지수와 가장 상관관계가 높으며, 다음으로 상관관계가 높은 변수는 최대파고, 스펙트럼 의 대역폭, 유의파첨도 순이다. 주축해석을 통해 첨도와 비대칭 도의 변화율의 방향이 이상지수의 변화율의 방향과 거의 일치 하는 것을 볼 수 있었다. 각종 파고들의 변화율의 방향이 서로 비슷하며, 각종 주기들의 변화율도 방향이 서로 비슷한 것을 볼 수 있었다. 상관계수와 주축해석을 종합하면 Freak wave의 예측 에는 첨도 $\kappa$ 와 비대칭도 $\gamma$ 가 가장 중요한 변수이다. 이 논문에 서 제시한 결과들은 향후 Freak wave 특성 연구와, Freak wave 예측 모델을 구축하고 검증할 수 있는 자료로 쓰일 수 있을 것 이다.

\section{후기}

The author would like to thank Dr. Sverre K. Haver of Statoil for kindly providing the Draupner wave data.

\section{References}

James, G., Witten, D., Hastie, T., Tibshirani, R., 2015. An Introduction to Statistical Learning with Applications in R. Springer, New York. https://doi.org/10.1007/978-1-4614-7138-7

Kalif, C., Pleinovsky, E., Slunyaev, A., 2009. Rogue Waves in the Ocean. Springer, Berlin Heidelberg. https://doi.org/10.1007/ 978-3-540-88419-4

Kim D., 2010 An Analysis of Statistical Characteristics of Nonlinear Ocean Waves. Journal of the Korean Society for Marine Environment and Energy, 13(2), 112-120.

Kim, D., 2013a. On the Statistical Characteristics of the New Year Wave. Journal of Ocean Engineering and Technology, 27(1), 102-108. https://doi.org/10.5574/KSOE.2013.27.1.102

Kim, D., 2013b. The Effect of Sampling Rate on Statistical Properties of Extreme Waves. Journal of the Korean Society for Marine Environment and Energy, 16(1), 36-41. https://doi.org/10.7846/ JKOSMEE.2013.16.1.36

Liu, P.C., Pinho, U.F., 2004. Freak Waves-more Frequent that Rare!. Annales Geophysicae, European Geosciences Union, 22(5), 1839-1842.

Mori, N., Paul, C.L., Yasuda, T., 2002. Analysis of Freak Wave Measurements in the Sea of Japan. Ocean Engineering, 29(11), 1399-1414. https://doi.org/10.1016/S0029-8018(01)00073-7

Mori, N., 2004. Occurrence Probability of a Freak Wave in a Nonlinear Wave Field. Ocean Engineering, 31(2), 165-175. https://doi.org/ 10.1016/S0029-8018(03)00119-7

National Ocean Service, 2019. What is a Rogue Wave? <https:/ oceanservice.noaa.gov/facts/roguewaves.html $>$ [Accessed 21 Mar. 2019].

Stansell, P., 2004. Distributions of Extreme Wave, Crest and Trough Heights Measured in the North Sea. Ocean Engineering, 32(8-9), 1015-1036. https://doi.org/10.1016/j.oceaneng.2004.10.016 